\title{
Lack of effect on blood lipid and calcium concentrations of young men on changing from white to wholemeal bread
}

\author{
By K. W. HEATON, A. P. MANNING AND M. HARTOG \\ University Department of Medicine, Bristol Royal Infirmary, Bristol BS2 $8 \mathrm{HW}$
}

(Received 2 I Fanuary I975-Accepted 29 fuly 1975)

\begin{abstract}
I. When nineteen 'free-living' male students, who normally ate 231 (SEM I4) g white bread/d changed to wholemeal bread for a I9-week period, there was no significant change in body-weight, plasma cholesterol or plasma triglyceride levels. These values, as well as plasma concentrations of calcium, phosphate, urate and haemoglobin, remained essentially the same as those for a control group.

2. Increasing the wheat-fibre intake by eating wholemeal bread is not an effective method for reducing blood lipid levels, at least in heaithy young men with a moderate bread intake.
\end{abstract}

Recently we reported the unexpected finding that the administration of raw wheat bran (median $38 \mathrm{~g} / \mathrm{d}$ ) to sixteen middle-aged subjects for about 6 weeks was associated with a decrease in fasting plasma triglyceride and plasma calcium concentrations (Heaton \& Pomare, 1974). The present experiment was designed to study these phenomena over a longer period of time, using a more convenient source of cereal fibre, namely wholemeal bread.

\section{METHODS}

\section{Subjects}

Volunteers were recruited from Bristol University, mainly students from the medical school. All volunteers were male, aged 19-23 years and in good health. Conditions for entry to the study were that the subject $(a)$ normally ate exclusively white bread, at least five slices daily, and no bran cereals and $(b)$ was prepared to change his type of bread to exclusively wholemeal and continue this, with an otherwise unchanged diet, for 20 weeks. The subjects were told that the experiment was designed to study a possible link between dietary fibre and heart disease.

\section{Plan of experiment}

The study began with a 2- or 3-week 'run-in' period of continued white bread eating, during which the subjects were seen three times for recording of body-weight and for blood sampling. To enable the intake of white bread to be estimated, each subject recorded on a special chart the number of slices of bread eaten over a $7 \mathrm{~d}$ period and brought for weighing two representative slices. Sucrose intake was assessed by means of a dietary questionnaire devised by the Department of Dietetics and administered by one of us. At the same time, information was obtained about alcohol consumption and the use of butter or margarine on bread.

On I or 8 February 1974, twenty subjects began eating bread made from '100\%extraction' wholemeal flour (stone-ground flour; Allinson's Ltd, Castleford, Yorks.). 
This flour contains I02-1 $12 \mathrm{~g}$ dietary fibre $/ \mathrm{kg}$, expressed as unavailable carbohydrate and lignin (Fraser, 1958; Southgate, 1969), compared with $32 \mathrm{~g} / \mathrm{kg}$ in white flour (Fraser, 1958). The bread was supplied as standard small loaves from a single baker at two convenient distribution points, $3 \mathrm{~d} /$ week. The number of loaves taken by each subject was recorded until the study ended in mid-June 1974. One student did not complete the study because of difficulty in reaching the bread distribution points. All the others co-operated fully throughout the study. The Easter vacation took some of the subjects away from Bristol for 3 or 4 weeks, but all were able to continue eating Allinson's or equivalent wholemeal bread bought or made locally. Blood samples were obtained $4,7,11,16$ and $19-20$ weeks after starting to eat wholemeal bread. Apart from attending to collect bread and provide blood samples, all subjects continued their normal lives. Half-way through the study the subjects were asked to report in writing any subjective effects they had noticed after changing their type of bread consumption. At the end, sucrose intake was assessed for a second time.

The control group consisted of sixteen healthy young men aged $19-26$ years (five students and eleven doctors), in whom fasting venous blood samples were obtained in February, March, May and June 1974. Sucrose and alcohol intake was also assessed in February and June 1974.

\section{Blood analyses}

Fasting venous blood samples were obtained without stasis and after at least $24 \mathrm{~h}$ abstention from drinking alcohol. Plasma samples for lipid estimations were separated from whole blood and stored at $-20^{\circ}$. All samples from each subject were analysed at the same time. Cholesterol and triglyceride concentrations were estimated using an AutoAnalyzer (Technicon Instruments Co. Ltd, Basingstoke, Hants) and, with minor modifications, the methods of Rappaport \& Eichhorn (1955) and of Kessler \& Lederer (1965) respectively. Plasma levels of $\mathrm{Ca}$, phosphate, urea, urate and glucose were estimated after each blood-sampling session, using standard AutoAnalyzer methods. Blood counts were done using a Coulter counter (Coulter Electronics Ltd, High St South, Dunstable, Beds.). Body-weights were measured, using the same weighing scales, by trained nursing staff.

Results were analysed statistically using paired and unpaired $t$ tests as appropriate.

\section{RESULTS}

For the experimental subjects, the estimated mean intake of white bread before the study was 23I (SEM I4) g/d. During the study, the intake of wholemeal bread, as assessed by the numbers of loaves collected, was consistently less than this and averaged I8I (SEM 6) g/d. When the subjects were questioned half-way through the trial, none said they disliked wholemeal bread and most said they now preferred it to white bread. Fourteen subjects replied in writing to the question regarding subjective effects of the change in bread. Of these, twelve commented on their stools, nine saying that they were more frequent or softer, two that there was no change and one that the stools were harder. Sucrose intake ranged from 39 to $\mathrm{r} 16 \mathrm{~g} / \mathrm{d}$ at the beginning of the study and from 25 to $153 \mathrm{~g} / \mathrm{d}$ at the end of the study, for the experimental subjects, 
Vol. 35

ธิ๊

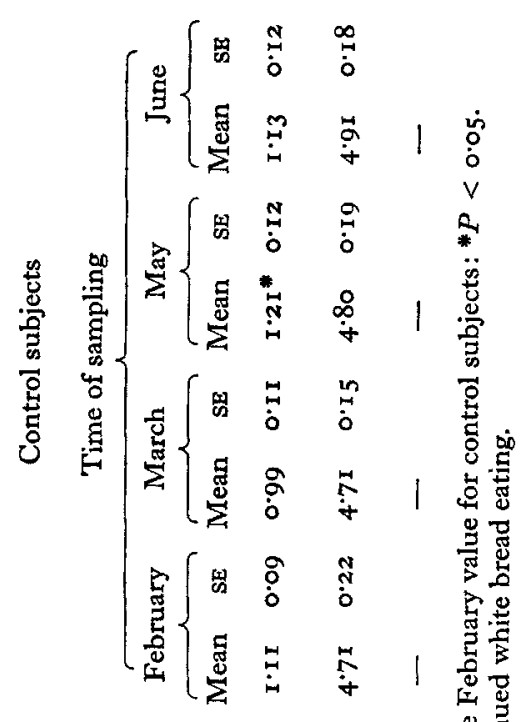

केष

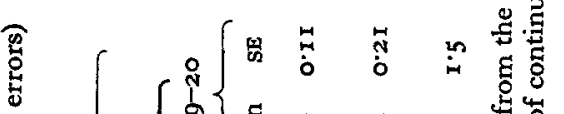

so

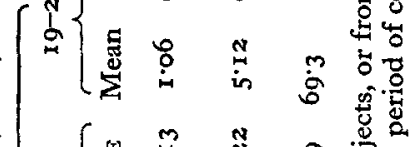

है

है

.

है है

○

s

कू

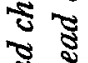

है

ฐ

ذิำ

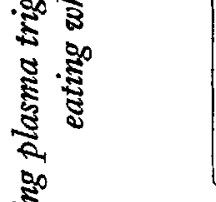

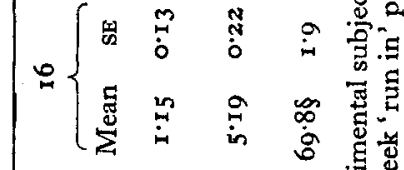

橧

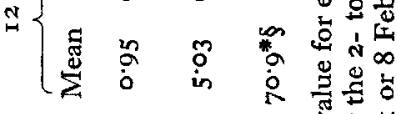

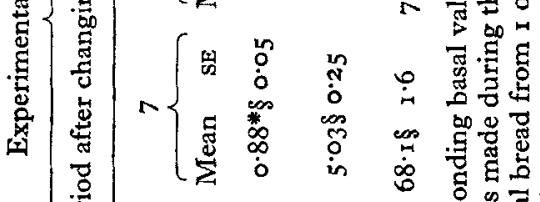

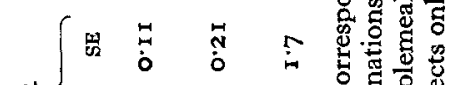

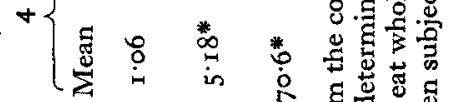

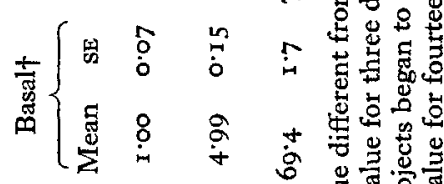

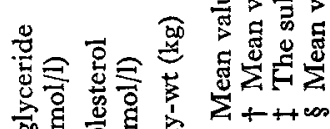

总起 
Table 2. Fasting plasma calcium, phosphate, urea, urate and glucose concentrations and blood haemoglobin levels for nineteen adult male subjects (aged I9-23 years) eating wholemeal bread and for a control group of sixteen adult male subjects (aged 19-26 years)

(Mean values with their standard errors)

Fasting plasma concentration ( $\mathrm{mmol} / \mathrm{l})$

\begin{tabular}{|c|c|c|c|c|c|c|c|c|c|c|c|c|}
\hline & & \multirow{2}{*}{\multicolumn{2}{|c|}{$\begin{array}{l}\text { Haemo- } \\
\text { globin }(g / 1)\end{array}$}} \\
\hline & \multicolumn{2}{|c|}{$\mathrm{Ca}$} & \multicolumn{2}{|c|}{ Phosphate } & \multicolumn{2}{|c|}{ Urea } & \multicolumn{2}{|c|}{ Urate } & \multicolumn{2}{|c|}{ Glucose } & & \\
\hline & Mean & SE & Mean & SE & Mean & SE & Mean & SE & Mean & SE & Mean & $\mathbf{S E}$ \\
\hline $\begin{array}{l}\text { Experimental } \\
\text { subjects }\end{array}$ & $2 \cdot 56$ & 0.02 & $I \cdot I 7$ & 0.03 & 4.97 & 0.27 & 0.39 & 0.01 & 3.41 & 0.11 & $\mathbf{I}^{52}$ & 2 \\
\hline Control subjects & $2 \cdot 54$ & 0.02 & $1 \cdot 22$ & 0.04 & $4 \cdot 56$ & 0.28 & 0.36 & 0.02 & $3 \cdot 56$ & 0.07 & I5 I & 2 \\
\hline
\end{tabular}

and for the control subjects the corresponding values were $12-105$ and $0-134 \mathrm{~g} / \mathrm{d}$; the differences were not statistically significant for either group. During the study, there was no change in alcohol intake or in the type of fat spread on the bread.

At the start of the study all subjects and controls had normal levels of fasting plasma lipids, $\mathrm{Ca}$, phosphate, urea, urate and glucose and normal blood counts. Table I gives a summary of the values for plasma triglyceride and cholesterol concentrations for the two groups of subjects, and the body-weights for the experimental subjects. At the end of the study, there was no significant change in any of these measurements in either group.

At the end of the study there was no significant difference between the experimental and control groups in respect of fasting plasma glucose, $\mathrm{Ca}$, phosphate, urea or urate, or of blood haemoglobin concentration (Table 2).

\section{DISCUSSION}

The results of this study have indicated that, in healthy, 'free-living' young men eating greater than average amounts of bread, changing from white to wholemeal bread has no significant effect on body-weight, plasma cholesterol or fasting plasma triglyceride concentrations. It is unlikely that a genuine effect occurred that was masked by unintentional changes in the other components of the diet, because there was no change in sucrose or alcohol intake, or in the type of fat spread on the bread. Although intakes of white and wholemeal bread were assessed by different methods, making comparison difficult, it is possible that the amount of bread eaten decreased on changing to wholemeal. If this was so the intake of saturated fat as butter or margarine could have decreased. Nevertheless, there was no tendency for the plasma cholesterol to decrease during the period of eating wholemeal bread. Other changes which might have influenced the plasma triglyceride levels were not apparent; bodyweight, sucrose intake and alcohol consumption remained constant.

No similar studies have been published with which these findings can be compared. We have previously found a decrease in plasma triglyceride and $\mathrm{Ca}$ concentrations when subjects ate wheat bran (Heaton \& Pomare, 1974). Bran is of course the main 
additional component in wholemeal bread as compared with white bread. However, in wholemeal bread, bran has been subjected to fermentation by yeast and to baking, which may well alter its properties. More important, the subjects previously given bran were quite different from the student volunteers in the present study. The former were all middle-aged and many were overweight. Their initial triglyceride levels were on average $34 \%$ higher $(\mathrm{I} \cdot 34 \mathrm{v} . \mathrm{I} \cdot 00 \mathrm{mmol} / \mathrm{l})$. It is presumably more difficult to reduce a triglyceride level which is already low. The intake of bran in the two studies was similar. On the basis that wholemeal flour contains $112 \mathrm{~g}$ dietary fibre $/ \mathrm{kg}$ (i.e. unavailable carbohydrates and lignin (Southgate, 1969 )), and that bran contains about $350 \mathrm{~g}$ dietary fibre/kg (D. A. T. Southgate, personal communication), the intake of the subjects in the present study was equivalent to about $39 \mathrm{~g}$ bran/d. In our earlier study the median intake of bran was $3^{8} \mathrm{~g} / \mathrm{d}$.

The failure of plasma cholesterol levels to decrease after 19 weeks on a moderately high intake of wholemeal bread lends no support to the hypothesis (derived mainly from animal experiments) that dietary fibre is a hypocholesterolaemic agent in man (Trowell, 1972). However, the subjects in the present study began with a relatively low plasma cholesterol level, and a different result might have been obtained had they started at a higher level. Conceivably a higher intake of wholemeal bread would be effective. In a study by Mathur, Khan \& Sharma (1968) of the hypocholesterolaemic properties of a pulse, Bengal gram (chick pea; Cicer arietinum), an intake of $400 \mathrm{~g} / \mathrm{d}$ was used. However, it is doubtful if normal British subjects could be persuaded to eat $400 \mathrm{~g} / \mathrm{d}$ of any single food item. Since these experiments were completed other workers (Jenkins, Leeds, Newton \& Cummings, r975; Truswell \& Kay, 1975) have reported negative results with respect to the effects of wheat fibre on the plasma cholesterol concentrations of human subjects.

The failure of wholemeal bread to lower plasma $\mathrm{Ca}$, which again differs from our experience with bran, may also be due to a change in the properties of bran during bread-making. During the leavening of the dough the phytic acid in wheat is largely destroyed by phytase (myo-inositol hexakinophosphate I- and 6-phosphohydrolases; $E C$ 3.1.3.8 and $E C$ 3.1.3.26 respectively) (Davidson \& Passmore, 1969). In an earlier report, it was found that over an II $\mathrm{d}$ period, a diet containing much larger amounts of wholemeal bread than in the present study (average $637 \mathrm{~g}$ dry weight/d) induced a negative $\mathrm{Ca}$ balance in six normal subjects and tetany in one subject (McCance \& Walsham, I948). However, Ca intakes in that study were low compared with those found with more normal diets such as those of our volunteers. The present finding of normal plasma $\mathrm{Ca}$ after 19 weeks with a moderate intake of wholemeal bread suggests that $\mathrm{Ca}$ depletion may occur only with abnormally large intakes of wholemeal bread. Furthermore, there may, in the long term, be compensation for reduced $\mathrm{Ca}$ absorption (Walker, 1972 ).

The authors are indebted to the volunteers and to the staff of the Chemical Pathology and Haematology Departments of the Bristol Royal Infirmary, and gratefully acknowledge financial help from Allinson's Ltd and Kellogg's of Great Britain Ltd. 


\section{REFERENCES}

Davidson, S. \& Passmore, R. (1969). Human Nutrition and Dietetics, 4th ed., p. I51. Edinburgh: E. \& S. Livingstone.

Fraser, J. R. (1958). F. Sci. Fd Agric. 9, 125.

Heaton, K. W. \& Pomare, E. W. (1974). Lancet i, 49.

Jenkins, D. J. A., Leeds, A. R., Newton, C. \& Cummings, J. H. (1975). Lancet i, I I 6.

Kessler, G. \& Lederer, H. (1965). In Technicon Symposium: Automation in Analytical Chemistry, p. 345 [L. T. Skeggs, editor]. New York: Mediad Inc.

McCance, R. A. \& Walsham, C. M. (r948). Br. .. Nutr. 2, 26.

Mathur, K. S., Khan, M. A. \& Sharma, R. D. (1968). Br. med. F. i, 30.

Rappaport, F. \& Eichhorn, F. (1955). Revta méd. Córdoba 43, 86.

Southgate, D. A. T. (1969). F. Sci. Fd Agric. 20, 33 I.

Trowell, H. C. (1972). Am. F. clin. Nutr. 25, 926.

Truswell, A. S. \& Kay, R. M. (1975). Lancet $1,923$.

Walker, A. R. P. (1972). Am. F. clin. Nutr. 25, 5 I8. 